\title{
ОБЩИЕ ПРЕДСТАВЛЕНИЯ О БИЛИНГВИЗМЕ В ПСИХОЛОГИИ
}

\author{
С. Ю. Свитюк \\ Иркутский нацииональный исследовательский технический университет, г. Иркутск, Российская Федерация
}

\section{ИНФОРМАЦИЯ О СТАТЬЕ}

Дата поступления

19 сентября 2017 г.

Дата принятия к печати 11 декабря 2017 г.

Дата онлайн-размещения 27 декабря 2017 г.

\section{КАЮЧЕВЫЕ САОВА}

Билингвизм, билингвальная личность, двуязычный индивид, речевая деятельность, психический механизм, общение

\begin{abstract}
АННОТАЦИЯ
В статье освещаются общие представления, сущность содержания понятия билингвизма в психологии, а также его трактовки с различных точек зрения. Проведен анализ литературы отечественных и зарубежных авторов по проблематике изучения билингвизма, кратко изложены основные билингвистические идеи, теории в различных подходах: лингвистическом, социологическом, социолингвистическом, лингвокультурологическом, педагогическом в сравнении с психологическим аспектом двуязычия. Отражены основные особенности билингвизма как психологического явления, определен основной круг проблем исследования билингвизма в психологии. Описаны различные виды билингвизма и основы психологической типологии билингвизма, а также психологические факторы, которые оказывают влияние на формирование определенного типа билингвизма, рассмотрены особенности формирования билингвальной личности. Билингвизм рассматривается как сложный психологический феномен, характеризующийся знанием второго языка, проявляющий способности к овладению вторым языком, умеющий интегрироваться во вторичный социум благодаря приобретению социального опыта путем познания культуры, ценностей культуры другого народа, образа его жизни в результате овладения двумя языками.
\end{abstract}

\section{GENERAL CONCEPTS OF BILINGUALISM IN PSYCHOLOGY}

\author{
Svetlana Yu. Svituk \\ Irkutsk National Research Technical University, Irkutsk, Russian Federation
}

\section{ARTICLE INFO}

Received

September 19, 2017

Accepted

December 11, 2017

Available online

December 27, 2017

\section{KEYWORDS}

Bilingualism, bilingual personality, bilingual individual, speech activity, mental mechanism, communication

\begin{abstract}
The article represents general concepts, the nature and the content of the concept of bilingualism in psychology, its interpretation from various points of view. The literature of Russian and foreign authors on the problems of studying bilingualism is analyzed, basic bilingual ideas, theories in various approaches are described: linguistic, sociological, sociolinguistic, linguacultural, pedagogical in comparison with the psychological aspect of bilingualism. The main features of bilingualism as a psychological phenomenon are described, the basic problems of bilingualism research in psychology are determined. Various forms of bilingualism and the basis of the psychological typology of bilingualism are described, as well as the psychological factors that influence the formation of a certain type of bilingualism, and the features of the formation of a bilingual personality are considered. The author sees bilingualism as a complex psychological phenomenon, characterized by the knowledge of a second language, displaying the ability to master a second language, to integrate into secondary society through the acquisition of social experience by the perception of different culture and cultural values of other people, the way of their life as the result of mastering two languages.
\end{abstract}

Проблема исследования билингвизма в современном поликультурном обществе особенно актуальна в последнее время. Речевая деятельность является средством самовыражения и самоутверждения каждой нации, средством выражения национального духа народа, его национальной самобытности. Билингвизм позволяет преодолевать наци- ональные преграды, обеспечивает речевую коммуникацию между собой всех членов полиэтнического общества, говорящих на разных языках.

Очень часто значение слова «билингвизм» приравнивается к значению слова «двуязычие», то есть эти два слова нередко используются как понятия с синонимичным значе- 
нием. Что касается трактовок значения этих терминов, то мы можем встретить большое их количество в различных источниках. Одно из определений, например, говорит, что билингвизм это владение двумя языками, и оба этих языка действительно употребляются с целью общения довольно часто [1]. Так, У. Вайнрайх билингвизм определяет как практическое использование двух языков попеременно [2]. А. Д. Швейцер уточняет, что первым языком считается родной, а вторым - неродной, который повсеместно используется той или иной национальной общностью. Уровень владения двумя языками может быть отнюдь не одинаковым, могут быть различия в уровне владения использования языка при устном и письменном общении, то есть одной из этих форм человек может владеть лучше, а другой значительно хуже [3]. В. Ю. Розенцвейг говорит, что двуязычие это не только достаточный уровень владения двумя языками, а также и умение переключаться с одного языка на другой исходя из коммуникативной задачи [4]. Р. К. Миньяр-Белоручев считает, что знание двух языков это и есть билингвизм [5]. Л. Л. Нелюбин определяет билингвизм как эквивалентное владение двумя языками [6]. Также билингвизмом называют функционирование двух языков, которое призвано обслуживать нужды всего этноса в целом, а также членов этого этноса по отдельности. Билингвизм это не простое знание второго языка на одном уровне с родным, а адекватное использование каждого из языков в соответствующих жизненных обстоятельствах [7]. Еще в одной трактовке билингвизм определяется как владение двумя разными языками или диалектными формами одного языка на уровне, которого достаточно для осуществления коммуникации и рассматривается с точки зрения психологического и социального подходов. Владеть двумя языками может как группа людей, так и конкретный человек индивидуально. Если рассматривать значение понятия «Двуязычие» в узком смысле, то можно сказать что, это равнозначное владение двумя языками в совершенстве, а в широком смысле - уровень владения вторым языком является относительным и предполагает умение применять его в конкретных ситуациях общения [1].

В психологии билингвизм трактуется как владение двумя языками и как умение одинаково ими пользоваться исходя из коммуникативной ситуации. Е. М. Верещагин, например, рассматривает двуязычие как психический механизм, который позволяет человеку порождать и воспроизводить речевые высказывания, принадлежащие к двум языковым системам, параллельно [8]. Н. Б. Мечковская определяет двуязычие как употребление одним и тем же индивидом нескольких языков в зависимости от коммуникативной задачи [9]. А. А. Леонтьев называет билингвом человека, который умеет осуществлять речевую деятельность и использует языковые средства обоих языков, учитывая ближайшее социальное окружение, цель коммуникации и обладает некоторой информацией о своем партнере по общению и имеет относительную свободу при выборе языка для осуществления общения [10]. Билингвизм как психологический феномен предполагает владение двумя языками на одинаково хорошем уровне и умение использовать оба эти языка в различных условиях общения. Кроме этого, отличительной чертой двуязычия является способность билингвов легко осуществлять переключение с одного языка на другой, исключая их смешение в процессе общения [11].

Анализ литературы отечественных и зарубежных авторов показал, что проблематика билингвизма имеет большой интерес среди ученых. Имеются различные концепции и теории относительно билингвизма, которые отражены в разнообразных аспектах. Билингвизм рассматривается в лингвистическом, педагогическом, социологическом, социолингвистическом, лингвокультурологическом, психологическом и некоторых других аспектах. Изучением явления билингвизма в лингвистике занимались такие ученые, как: В. Ю. Розенцвейг, М. М. Михайлов, В. А. Виноградов, Ю. А. Жлуктенко и др., в психологии: Н. В. Имедадзе, А. А. Леонтьев, Л. С. Выготский, Е. М. Верещагин и др., в социологии: М. В. Дьячков, Ф. П. Филин, Ю. Д. Дешериев и др., в педагогике Р. К. Миньяр-Белоручев, Т. М. Савельева, В. С. Худницкий, В. А. Аврорин, Р. Ю. Барсук, М. М. Фомин и другие. Так, например, социологический аспект изучения билингвизма состоит в том, чтобы определить объем сфер применения и общественных функций каждого из двух языков, которые использует двуязычное население. Анализ билингвизма в социологической науке предполагает определение распространенности двуязычия среди мультинациональных трудовых общностей, влияния воздействия на двуязычие внеязыковых условий, например, 
таких как, этническая и классовая принадлежность, демографические параметры, социальная структура общества и пр., пути становления билингвизма, использование двуязычия в основных сферах общественной жизни и др. Данный аспект предполагает рассмотрение таких пунктов, как: способ изучения человеком или целой группой второго языка; территория, на которой двуязычие распространено; частота использования двух языков в сельской или городской местности; существование социальных и демографических групп [12]. Задача педагогического аспекта это создание и использование методов, изучающих сам процесс овладения двумя языками в условиях билингвизма, а также разработка методов для непосредственного изучения этих языков. Также педагогический подход к билингвизму рассматривает вопросы, связанные с активным и пассивным знанием языков [13]. С точки зрения лингвокультурологии билингвизм предполагает, что носители языка выстраивают свою коммуникацию в соответствии с конкретной языковой картиной мира, так как каждый из языков, который используется билингвом, обладает своими способами осмысления реальной действительности. Целью лингвистического подхода является исследование употребления языка людьми как средства для осуществления общения. Так, У. Вайнрайх говорит, что в двуязычии необходимо дать описание тех нескольких языковых систем, из-за которых происходит затруднение параллельного владения этими языками, выявить возможные несоответствия употребления каждого языка с нормативными правилами использования той или иной языковой системы, возникающими из-за двуязычия, определить возможные проявления интерференции этих двух языков [2]. И. Ф. Протченко и Ю. Д. Дешериев считают, что основная задача в лингвистическом подходе к билингвизму заключается в том, чтобы проанализировать взаимное влияние языковых систем, их соотнесенность, взаимопроникновение и взаимодействие языков на морфологическом, фонологическом, лексико-семантическом, стилистическом и синтаксическом уровнях. Также ученые считают, что в лингвистическом подходе к двуязычию важно исследовать проявление интерференции при использовании обеих языковых систем [12].

Психологический подход к билингвизму, в отличие от лингвистического, который ис- следует лингвистические явления, связанные с двуязычием, показывает особенности психологических механизмов формирования речи билингва. Изучение билингвизма с психологической точки зрения дает возможность понять соотносительную характеристику лингвистических категорий, понятий, существующих в языковом сознании билингвов; особенности запоминания, осознания, осмысления, восприятия билингвами понятий и категорий, характерных черт и особенностей, отличающихся во втором языке и отсутствующих в их языковом сознании как носителей первого языка [12]. Явление билингвизма в психологии имеет широкий спектр проблемных вопросов, например, взаимосвязь проблем билингвизма в психолингвистике и методов изучения неродного языка; мотивационные условия формирования билингвизма; иноязычные способности как психологическая предпосылка формирования билингвизма; взаимное влияние развития речи на родном и втором языках и др. [11]. В работах, посвященных психологии становления личности в условиях двуязычия, таких ученых как И. А. Зимняя, Н. В. Имедадзе, Т. М. Савельева, А. И. Яцикевичус, Б. А. Бенедиктов, 3. М. Хизроева, Е. М. Верещагин и др., изучены особенности формирования билингвизма, основные мотивационные основы и психологические механизмы овладения вторым языком. В психолингвистическом аспекте билингвизма также в значительной мере исследуется влияние билингвизма на мышление человека. Так, например, Л. В. Щерба, принимая во внимание взаимосвязь речи и мышления, различал в сознании человека в условиях билингвизма такие виды сочетания языковых систем, как независимая связь при чистом билингвизме, и зависимая связь при смешанном типе двуязычия. Независимая связь предполагает, что сосуществующие языки имеют две независимые системы ассоциаций в сознании человека, а зависимая контактирующие языки образуют только одну систему ассоциаций [14]. Н. А. Любимова полагает, что психологическую типологию двуязычия можно построить, учитывая следующее: метод владения языком, взаимосвязь мышления и речи на каждом из языков; виды речевой деятельности; соотношение механизмов речи, которые обеспечивают владение разными языками [15]. Изучение билингвизма в психологии включает изучение как механизмов производства, так и восприятия 
речи. Например, И. А. Зимняя, исследуя проблематику формирования билингвизма, полагает, что при организации образовательноязыковой стратегии необходимо учитывать четыре общепринятых фундаментально важных характерных черты языка. Одна из них рассматривает язык в качестве общественно-исторического результата, который отражает в себе историю, отношения в социуме, культуру, обычаи, традиции определенного этноса. Следующая характерная черта - это своеобразие отражения в языке в процессе коммуникации окружающей действительности. В третьей характеристике язык выступает как форма проявления сознания. Четвертая характеристика основывается на том, что язык это основной способ общения. Данные характеристики не зависят от конкретной языковой системы и их необходимо рассматривать в отношении родного и неродного языков [13]. Виды двуязычия или билингвизма в психологическом плане анализируется в различных аспектах. Так, Н. В. Имедадзе в своих исследованиях выделяет следующие типы билингвизма: доминантный - сбалансированный билингвизм, данная типология базируется на основе количественного соотношения двух систем языка; и совмещенный или смешанный - координированный или координативный билингвизм, в основе этих типов двуязычия - степень использования двух языков автономно [16]. По соотнесенности речи на каждом из языков с мышлением выделяется непосредственный и опосредованный характер связи и, соответственно, речь идет о выражении мысли, действительности мысли и дискурсивно-логических речевых умениях [17]. По числу выполняемых действий выделяют рецептивный, репродуктивный (воспроизводящий) и продуктивный (производящий) билингвизм [8]. По соотнесенности двух речевых механизмов между собой выделяют чистый и смешанный билингвизм [14]. И. Л. Медведева, А. А. Залевская выделяют следующие виды билингвизма: естественный и искусственный. При естественном билингвизме овладение двумя языками происходит при непрерывном нахождении и непосредственном общении в обеих языковых средах. Искусственный билингвизм означает, что овладение вторым неродственным языком возможно при специальном его изучении. В результате общения у естественного билингва происходит полное замещение языка и культуры с род- ного на иностранный язык. У искусственного билингва данный процесс невозможен, т.к. он бессознательно производит перевод, проигрывая ситуацию в рамках своей культуры. При искусственном билингвизме изученный язык в школьном возрасте или еще позднее навсегда становится «чужим» языком, при естественном же билингвизме - замещение языков решается в каждом конкретном случае. Естественный билингвизм - это способ мышления и целостность дуальной картины мира, а искусственный билингвизм - это возможность общения и расширения знаний о культуре иного народа [18]. Так, можно сказать, что билингвизм в психологии является методом и средством познавательных процессов, так как выступает необходимым элементом структуры современной коммуникации и культуры личности.

Проблема взаимодействия и соединения двух национальных картин мира и языковых систем является основной психологической особенностью процесса формирования билингвизма. Специфика этого феномена состоит в нереальности однозначной констатации его существования или отсутствия у конкретного человека. Мы можем только говорить лишь о сформированности одного из типов билингвизма [19]. Анализ факторов, оказывающих влияние на формирование определенного типа двуязычия, дает возможность объяснения многих психических процессов, появляющихся при билингвизме. Такими факторами являются: возраст, в котором происходит процесс овладения вторым языком, языковая практика и то, каким образом происходит овладение вторым языком. Е. Ю. Протасова, например, указывает, что первостепенную важность для качества усвоения второго языка имеет возраст, когда начинается его освоение. Ели это происходит до трехлетнего возраста, то можно говорить о двойном усвоении языков. Если позже трехлетия, то это первичное и вторичное усвоение языков, позже шестнадцатилетнего возраста - это только лишь усвоение второго языка. Объем изучения того или иного языка на занятиях и то, какой язык дети используют, общаясь с другими, оказывает значительное влияние на результат обучения второму языку [20]. Способность вступать в иноязычную коммуникацию, направляя свое сознание на предмет содержания, а не формы речевой деятельности, является одной из главных психологических характеристик 
сформированности билингвальных умений. В таком случае, эффективность использования второго языка является одним из основных показателей сформированности билингвальных умений [11].

Попытаемся понять, что представляет собой билингвальная личность с точки зрения психологии. В современных психологических и психолингвистических источниках личность определяется как комплекс определенных свойств и качеств человека, уникальности его характера, темперамента, социокультурного опыта, знаний, поведения, его отношения к окружающему миру, к окружающим людям, к самому себе. Так как индивидуальное двуязычие может оказывать влияние на психическую организацию личности билингва, проявляющейся в его социальнообщественном взаимодействии и деятельности, то принципы становления двуязычия необходимо дополнить и принципами влияния билингвизма на развитие психического строя личности билингва [18].

Следовательно, феномен явления билингвизма в психологии неразрывно связан с проблемой формирования билингвальной личности, которая владеет и пользуется двумя языками - родным и вторым неродным - в одинаковой мере свободно. Свободное владение языками основано на усвоении языковой картины мира народов, говорящих на разных языках, когда билингв усваивает языковые средства вместе с материальной и духовной культурой народов - носителей этих языков. Наиболее важным для формирования билингвальной личности является овладение речевой деятельностью и умение общаться во всех сферах жизни на двух языках, а также развитие в сознании билингва двух картин мира, что будет способствовать вхождению билингва в новую социальную и культурную действительность [11]. На основании всего выше изложенного можно сказать, что билингвальная личность как психологический феномен - это личность, которая владеет двумя языковыми системами и их средствами, активно использует их для осуществления коммуникации, а также усвоившая культуру и национальную картину мира обоих изученных языков. Таким образом, билингв - это личность, прошедшая социализацию во втором социуме, поэтому как член второго общества знает его социально-культурные нормы и отношения в нем. Данная личность также успешно осуществляет межкультурную коммуникацию, так как знает этнические нормы второго культурного сообщества, ориентируется в них и формирует в своем вторичном когнитивном сознании представление об их целесообразном использовании.

Итак, билингвизм исследуется в различных науках, каждая из которых рассматривает двуязычие в своей трактовке. Но все отрасли науки, изучая билингвизм, основываются на существовании первичной языковой системы, которая используется для общения. Что касается явления билингвизма в психологии, то билингвизм представляет собой сложный психологический феномен, характеризующийся знанием второго языка, проявляющий способности к овладению вторым языком, умеющий интегрироваться во вторичный социум благодаря приобретению социального опыта путем познания культуры, ценностей культуры другого народа, образа его жизни в результате овладения двумя языками. Билингвом может быть названа личность, способная использовать в своем общении две языковые и культурно-национальные системы, являющаяся обладателем двух систем общения.

\section{Список использованной литературы}

1. Жеребило Т. В. Словарь лингвистических терминов. / Т. В. Жеребило. - Изд. 5-е, испр. и доп. - Назрань : Пилигрим, 2010. - 486 с.

2. Вайнрайх У. Одноязычие и многоязычие / У. Вайнрайх // Новое в лингвистике: языковые контакты / под ред. В. Ю. Розенцвейга. - М. : Прогресс, 1972. - Вып. 6. C. $25-51$.

3. Швейцер А. Д. Современная социолингвистика: Теория, проблемы, методы / А. Д. Швейцер. - М. : Наука, 1976. - 176 с.

4. Розенцвейг В. Ю. Основные вопросы теории языковых контактов / В. Ю. Розенцвейг / / Новое в лингвистике: языковые контакты / под ред. В. Ю. Розенцвейга. - М. : Прогресс, 1972. - Вып. 6. - С. 5-24.

5. Миньяр-Белоручев Р. К. Как стать переводчиком? / Р. К. Миньяр-Белоручев. - М. : Готика, 1999. - 176 с. 
6. Нелюбин Л. Л. Толковый переводоведческий словарь / Л. Л. Нелюбин. - 3-е изд. - М. : Наука, 2003. - 320 с.

7. Бурыкин А. А. Ментальность, языковое поведение и национально-русское двуязычие [Электронный ресурс] / А. А. Бурыкин // Мир слова русского. - Режим доступа: http:// abvgd.russian-russisch.info/articles/10.html.

8. Верещагин Е. М. Психологическая и методическая характеристика двуязычия (билингвизма) / Е. М. Верещагин. - М. : Изд-во Моск. ун-та, 1969. - 159 с.

9. Мечковская Н. Б. Социальная лингвистика / Н. Б. Мечковская. - 2-е изд., испр. - М. : Аспект Пресс, 2000. - 206 с.

10. Леонтьев А. А. Психолингвистические единицы и порождение речевого высказывания / А. А. Леонтьев. - 3-е изд., стереотип. - М. : КомКнига, 2005. - 312 с.

11. Боченкова М. Ю. Билингвизм и билингвальная среда как социокультурный и психолого-педагогический феномен / М. Ю. Боченкова // Концепт. - 2016. - Т. 2. - С. 591-595.

12. Дешериев Ю. Д. Основные аспекты исследования двуязычия и многоязычия / Ю. Д. Дешериев / / Проблемы двуязычия и многоязычия. - М. : Наука, 1972. - С. $26-42$.

13. Зимняя И. А. Психология обучения иностранным языкам в школе / И. А. Зимняя. М. : Педагогика, 1991. - 222 с.

14. Щерба Л. В. Языковая система и речевая деятельность / Л. В. Щерба. - Л. : Наука, 1974. -427 c.

15. Любимова Н. А. Фонетическая интерференция и общение не на родном языке (Экспериментальное исследование на материале финско-русского двуязычия) : дис. ... д-ра филол. наук / Н. А. Любимова. - Л., 1988. - 195 с.

16. Имедадзе Н. В. Некоторые вопросы типологии билингвизма / Н. В. Имедадзе / / Психологические и лингвистические аспекты проблемы языковых контактов : межвуз. темат. сб. - Калинин : Изд-во КГУ, 1978. - С. 31-41.

17. Беляев Б. В. Очерки по психологии обучения иностранным языкам / Б. В. Беляев. 2-е изд. - М. : Просвещение, 1965. - 229 с.

18. Залевская А. А. Психолингвистические проблемы учебного двуязычия: учебное пособие / А. А. Залевская, И. Л. Медведева. - Тверь : Твер. гос. ун-т, 2002. - 195 с.

19. Худобина О. Ф. Билингвальное образование как междисциплинарный феномен / О. Ф. Худобина // Известия Волгоградского государственного технического университета. 2005. - № 4 (13). - С. 161-163.

20. Протасова Е. Ю. Дети и языки / Е. Ю. Протасова. - М. : Центр инноваций в педагогике, 1998. - 167 с.

\section{References}

1. Zherebilo T. V. Slovar' lingvisticheskih terminov [Dictionary of linguistic terms]. $5^{\text {th }}$ ed. Nazran, Piligrim Publ., 2010. 486 p.

2. Weinreich U. Monolingualism and multilingualism. In Rosenzweig V. Y. (ed.) Novoe v lingvistike: yazykovye kontakty [The New in linguistics: language contact]. Moscow, Progress Publ., 1972, vol. 6, pp. 25-51. (In Russian).

3. Schweitzer A. D. Sovremennaja sociolingvistika: Teorija, problemy, metody [Contemporary sociolinguistics: Theory, problems, methods]. Moscow, Nauka Publ., 1976. 76 p.

4. Rosenzweig V. Y. The main issues of the theory of language contact. In Rosenzweig V. Y. (ed.) Novoe v lingvistike: yazykovye kontakty [The New in linguistics: language contact]. Moscow, Progress Publ., 1972, vol. 6, pp. 5-24. (In Russian).

5. Minyar-Beloruchev R. K. Kak stat' perevodchikom? [How to become an interpreter?]. Moscow, Gotika Publ., 1999. 176 p.

6. Nelyubin L. L. Tolkovyj perevodovedcheskij slovar' [Explanatory translatological dictionary]. Moscow, Nauka Publ., 2003. 320 p.

7. Burykin A. A. Mental'nost', jazykovoe povedenie i nacional'no-russkoe dvujazychie [Mentality, the language behavior and national-Russian bilingualism]. The World of Words. Avaible at: http:/ / abvgd.russian-russisch.info/articles/10.html.

8. Vereshchagin E. M. Psihologicheskaja i metodicheskaja harakteristika dvujazychija (bilingvizma) [Psychological and methodological characteristics of bilingualism]. Moscow State University Publ., 1969. $159 \mathrm{p}$.

9. Mechkovskaya N. B. Social'naja lingvistika: Posobie dlja studentov [Social linguistics: a handbook for students]. $2^{\text {nd }}$ ed. Moscow, Aspect Publ., 2000. 206 p.

10. Leont'ev A. A. Psiholingvisticheskie edinicy i porozhdenie rechevogo vyskazyvanija [Psycholinguistic units and generation of speech]. $3^{\text {th }}$ ed. Moscow, Komkniga Publ., 2005. 312 p. 
11. Bochenkova M. J. Bilingualism and bilingual environment as a socio-cultural and psychopedagogical phenomenon. Kontsept $=$ Concept, 2016, vol. 2, pp. 591-595. (In Russian).

12. Desheriyev Yu. D. Osnovnye aspekty issledovanija dvujazychija i mnogojazychija [Key aspects of the study of bilingualism and multilingualism]. Problems of bilingualism and multilingualism. Moscow, Nauka Publ., 1972, pp. 26-42. (In Russian).

13. Zimnyaya I. A. Psihologija obuchenija inostrannym jazykam v shkole [Psychology of teaching foreign languages at school]. Moscow, Pedagogika Publ., 1991. 222 p.

14. Shcherba L. V. Jazykovaja sistema i rechevaja dejatel'nost' [Language system and speech activity]. Leningrad, Nauka Publ., 1974. 427 p.

15. Lyubimova N. A. Foneticheskaja interferencija i obshhenie ne na rodnom jazyke (Jeksperimental'noe issledovanie na materiale finsko-russkogo dvujazychija). Dr. Diss. [Phonetic interference and the communication in foreign language (an experimental study on the material of the Finnish-Russian bilingualism). Dr. Diss.]. Leningrad, 1988. 195 p.

16. Imedadze N. V. Some problems of typology of bilingualism. Psikhologicheskie i lingvisticheskie aspekty problemy yazykovykh kontaktov [Psychological and linguistic aspects of language contact], Kalinin State University, 1978, pp. 31-41. (In Russian).

17. Belyaev B. V. Ocherki po psihologii obuchenija inostrannym jazykam [Essays on the psychology of teaching foreign languages]. $2^{\text {nd }}$ ed. Moscow, Prosveshchenie Publ.,1965. 229 p.

18. Zalevskaya A. A., Medvedeva I. L. Psiholingvisticheskie problemy uchebnogo dvujazychija: uchebnoe posobie [Psycholinguistic problems of educational bilingualism: a study guide]. Tver State University, 2002. 195 p.

19. Hudobina O. F. Bilingual education as an interdisciplinary phenomenon. Izvestiya Volgogradskogo gosudarstvennogo tekhnicheskogo universiteta = Izvestia Volgograd State Technical University, 2005, no. 4 (13), pp. 161-163. (In Russian).

20. Protasova E. J. Deti $i$ jazyk [Children and language]. Moscow, Tsentr innovatsii v pedagogike Publ., 1998. 167 p.

\section{Информация об авторе}

Свитюк Светлана Юрьевна - старший преподаватель, Иркутский национальный исследовательский технический университет, 664074, г. Иркутск, ул. Лермонтова, 83, e-mail: sveta-1984@inbox.ru.

\section{Для цитирования}

Свитюк С. Ю. Общие представления о билингвизме в психологии / С. Ю. Свитюк / / Психология в экономике и управлении. - 2017. - Т. 9, № 2. C. 26-32. - DOI: 10.17150/2225-7845.2017.9(2).26-32.

\section{Author}

Svetlana Yu. Svituk - Senior Lecturer, Irkutsk National Research Technical University, 83 Lermontov Street, 664074, Irkutsk, Russian Federation, e-mail: sveta-1984@inbox.ru.

\section{For Citation}

Svituk S. Yu. General concepts of bilingualism in psychology. Psikhologiya $v$ ekonomike $i$ upravlenii $=$ Psychology in Economics and Management, 2017, vol. 9, no. 2, pp. 26-32. DOI: 10.17150/2225-7845.2017.9(2).2632. (In Russian). 